\title{
Tecnologias digitais e o processo de protagonismo estudantil no Ensino Fundamental
}

\author{
Juliana Silva Arruda, José Aires de Castro Filho, Liliane Maria Ramalho de \\ Castro Siqueira, Rayssa Araújo Hitzschky, Maria Alinne Forte de Brito.
}

\author{
Instituto UFC Virtual \\ Universidade Federal do Ceará (UFC) \\ Campus do Pici - Bloco 901- $1^{\circ}$ andar- CEP 60.455-760- Fortaleza- CE \\ julianarruda24egmail.com; airesevirtual.ufc.br; \\ ramalholilianedyahoo.com.br; hitzschkyrayssaegmail.com; \\ alinefbritolgmail.com;
}

\begin{abstract}
Technological advances bring possibilites for the development of contemporary practices, from the insertion of computers into curricular activities. This study aimed to analyze how the computer, through digital resources, can mediate the emergence of student protagonism. The qualitative methodology was used, with an interpretive character. The research technique involved participant observation, and as instruments of data collection, videos and field journals. The results highlighted that resources, coupled with interaction between peers, facilitate the emergence of protagonism, leading to learning and facilitating actions and postures of authorship.
\end{abstract}

\begin{abstract}
Resumo. Os avanços tecnológicos acarretam possibilidades para o desenvolvimento de práticas contemporâneas, a partir da inserção de computadores em atividades curriculares. Este estudo teve por objetivo analisar como o computador, por meio de recursos digitais, pode mediar a emergência do protagonismo estudantil. Foi utilizada a metodologia qualitativa, com caráter interpretativo. A técnica de pesquisa envolveu a observação participante, e como instrumentos de coleta de dados, vídeos e diários de campo. Os resultados destacaram que os recursos, aliados à interação entre pares, facilitam a emergência do protagonismo, acarretando aprendizagem e facilitando atuações e posturas de autoria.
\end{abstract}

\section{Introdução}

As ferramentas digitais beneficiam o contexto educacional ao fornecer novas possibilidades e alternativas de recursos para a atuação e o protagonismo dos alunos. Bonilla [2012] considera que há uma integração entre as tecnologias e a educação, ressaltando a influência dos recursos digitais no processo de aprendizagem.

A disseminação da Internet faz com que modernos recursos tecnológicos sejam desenvolvidos em diferentes ambientes de aprendizagem, tornando a relação entre a tecnologia e a educação, essencial no âmbito educacional. $\mathrm{O}$ uso das tecnologias digitais nos meios escolares suscita a investigação do desempenho em sala de aula, o desenvolvimento das habilidades, a motivação dos aprendentes, a participação individual e em grupo [RESTA E LAFERRIÈRE, 2007]. 
Warschauer [2006] apresenta a inclusão social, advinda da evolução da tecnologia, como agente transformador da interação dos alunos com o contexto social. Sendo assim, a educação e a aprendizagem são pressupostos importantes para a construção de uma sociedade da informação. A utilização dos recursos digitais proporciona habilidades ao discente para transformar esta informação em conhecimento.

Segundo Baptista e Vieira [2015], as tecnologias digitais, quando bem relacionadas aos projetos pedagógicos, podem potencializar o desenvolvimento da aprendizagem, proporcionando uma maior motivação do aluno, através de atividades dinâmicas que favorecem a estruturação da criticidade dos discentes, e tornando-os aptos a atuar em seu ambiente cultural e social. Os estudos de Nascimento e CastroFilho[2016] apontam que o uso de dispositivos móveis possibilita o desenvolvimento de diferentes recursos multimídias, que demonstram potencial para facilitar a educação, essencialmente, quando há integração entre o professor e o objetivo pedagógico.

Considera-se, desse modo, que os recursos tecnológicos, quando não utilizados em todo o seu potencial pedagógico, podem não permitir a atuação e a autoria dos alunos. Os estudos de Valente [2014] apontam que o uso das Tecnologias de Informação e Comunicação- TIC pode ser um fator determinante de motivação para a constituição da autonomia, participação, de ações inovadoras e posturas críticas.

No Ensino Fundamental, as abordagens pedagógicas das TIC no processo de ensino e de aprendizagem têm sido pouco exploradas [NASCIMENTO; CASTROFILHO, 2016]. Sendo assim, surge o interesse do presente estudo em analisar a influência da tecnologia integrada aos processos pedagógicos no desenvolvimento da atuação e da participação dos alunos na constituição da sua aprendizagem. O estudo originou-se da seguinte questão: Como as tecnologias digitais podem facilitar o processo de protagonismo em educandos do Ensino Fundamental?

Partindo dessa problemática, define-se o objetivo geral deste estudo, que é investigar as tecnologias digitais como facilitadoras do processo de protagonismo em educandos do Ensino Fundamental. Como objetivos específicos, propõem-se: a) definir parâmetros identificadores do protagonismo estudantil; e b) descrever as características do contexto no qual o protagonismo ocorre.

A presente pesquisa, portanto, pretende trazer benefícios e subsídios para facilitar o processo de protagonismo estudantil, utilizando as tecnologias como recurso mediador. Justifica-se o estudo ao considerar que as tecnologias, a cada dia, se apresentam como uma realidade das escolas brasileiras, no entanto, muitas vezes, o seu verdadeiro potencial e a intensidade de suas contribuições para o processo de aprendizagem ainda é desconhecido.

\section{Referencial teórico}

A presente seção se relaciona com a temática teórica sobre a aprendizagem a partir de uma perspectiva sócio-histórica, considerando o uso da tecnologia como recurso que facilita a emergência do protagonismo.

\section{1. Tecnologia e aprendizagem em uma visão sócio histórica}

Para Vygotsky, as mudanças que ocorrem no ser humano ao longo do seu desenvolvimento possuem gênese nos meios culturais, sociais e históricos. Segundo 
Suanno [2013], a influência do meio exterior no mundo interior dos sujeitos deve ser analisada a partir dos processos de interações entre os seres humanos e o contexto em que ele está inserido.A teoria vygotskyana considera a aprendizagem, essencialmente, a partir da história social. Analisando-se de maneira mais específica de que forma ocorre a aprendizagem, as relações sociais são enfatizadas como fator essencial [MEIRA; SPINILLO, 2006].

Esses autores consideram o ser humano como um sujeito participante do seu processo de desenvolvimento. Assim, trazendo para o meio educacional: para que o aprendente se desenvolva, são necessárias ferramentas culturais e também da sua própria atividade e atuação no seu desenvolvimento [VYGOTSKY, 1994].

Kreijns, Kirschner e Jochems [2003] ressaltam que o ensino e a aprendizagem são processos ativos e de experiências compartilhadas, considerando que o educador age como um mediador e os aprendentes são participantes ativos, assumindo, portanto, responsabilidade por seu desenvolvimento. Com relação ao uso dos recursos tecnológicos na educação, é necessário que estes proporcionem a interação entre o grupo de estudantes e promovam diálogos para que a aprendizagem ocorra.

Os estudos desses autores indicam, no entanto, que os ambientes virtuais, por si só, não promovem a interação social e que os processos de aprendizagem desencadeados pelo uso da tecnologia não podem ser considerados, somente, pelo aspecto cognitivo, mas sim por fatores sociais, emocionais e culturais.

Nessa conjuntura, não somente a interação com o professor promove $\mathrm{o}$ desenvolvimento do educando, mas também e, essencialmente, a relação entre o educando e seus pares. Dessa forma, o discente pode ser mediador entre outro educando e o conhecimento que deseja alcançar.

\subsection{Protagonismo Estudantil}

Segundo Costa [2000], o significado da palavra protagonismo tem origem na fusão de duas palavras gregas: protos, que indica o principal, o primeiro; e agonistes, que se caracteriza por lutador, competidor. Em se tratando de protagonismo juvenil, considerase a participação ativa dos jovens centrando forças por uma transformação social.

$\mathrm{O}$ autor acima citado descreve o protagonismo juvenil como uma alternativa tangível da estruturação e prática da cidadania, simultaneamente, considerando o aprendente integrado ao desenvolvimento da identidade, autoconceito e autoestima. Considera-se que a efetiva ocorrência do protagonismo estudantil se dá quando os discentes conseguem tomar decisões, fazer escolhas e conduzir, de alguma maneira, as atividades. Dessa forma, o protagonismo permite que o aluno saia do papel de aluno receptor para aquele que participa e constrói seu processo de aprendizagem.

$\mathrm{Na}$ emergência do protagonismo estudantil, o educando consegue ir além do seu nível de desenvolvimento. Considera-se o aluno como sujeito ativo e participante do seu processo de aprendizagem, no qual este consegue vivenciar e ultrapassar situações, funções e papéis que, em seu dia a dia, não tinha a oportunidade de exercer.

Wertsch, Del Rio e Álvarez [1998] consideram que o sujeito deve participar do seu próprio processo de desenvolvimento, atuando junto com as ferramentas culturais. Colaço [2001] fala sobre a interação de pares, sendo influenciada por fatores culturais, sociais e históricos, a partir de uma realidade constituída pelos próprios 
VI Congresso Brasileiro de Informática na Educação (CBIE 2017)

Anais do XXIII Workshop de Informática na Escola (WIE 2017)

aprendentes.Dessa maneira, enfatiza-se que a participação dos alunos no seu processo de aprendizagem podem potencializar situações de protagonismo estudantil.

A próxima seção desenvolve a metodologia adotada para alcançar os objetivos desse estudo.

\section{Procedimentos metodológicos}

A natureza do estudo é qualitativa, ressaltando as observações e as estratégias utilizadas pelos aprendentes, através da análise e da interpretação das mesmas. Bogdan e Biklen [1994] definem o estudo qualitativo como rigoroso e sistêmico, considerando as hipóteses e as indagações da pesquisa que surgem no momento em que o estudo se desenvolve. Ressalta-se como meta a construção do conhecimento e não somente a emissão de opiniões sobre o contexto.

Meira [1994] acredita que a análise qualitativa de processos como a cognição e a aprendizagem se torna complexa, pois envolve mudanças sensíveis e breves de gestos e de comunicações. Assim, a presente investigação foi desenvolvida dentro do contexto do projeto EDigital, que teve a parceria da UFC Virtual e a Companhia Energética do Estado do Ceará. Seu objetivo foi desenvolver competências por meio do programa de formação da comunidade escolar, para a inclusão e o uso das TIC na Educação.

O projeto EDigital foi iniciado em 2013, com três segmentos de formação, que aliaram a tecnologia à Educação: i) formação de professores; ii) formação de alunos monitores e iii) desenvolvimento de projetos que envolviam a sustentabilidade. A formação dos educadores abordou a apropriação tecnológica, que se caracterizou pelo processo de apresentação de recursos digitais, e teve como principal meta, conscientizálos a tomar decisões, exercer sua autoria, e compartilhar com a comunidade escolar a aplicação da tecnologia na Educação. A formação de alunos monitores teve como objetivo promover a autonomia e o protagonismo dos alunos, através da troca de conhecimento com os pares e os educadores. Com a conclusão da formação, os alunos monitores acompanharam e auxiliaram as aulas com o uso dos recursos educacionais, juntamente, com a equipe docente da escola.

Durante o desenvolvimento do estudo, foi proposto aos aprendentes um projeto com base nos seguintes temas: educação ambiental, consciência crítica de sustentabilidade e das tecnologias. Os subtemas que o caracterizaram foram: energia, tratamento do lixo, prejuízo do consumo para o meio ambiente e reciclagem.

Esse projeto teve como objetivo promover a conscientização sustentável dos educandos, por meio da elaboração de várias atividades, como postagens na rede social Facebook, discussões, produção de vídeos, aula em campo, nas quais todas envolveram os temas e os subtemas em atividades interativas. $O$ trabalho foi desenvolvido no Laboratório de Informática Educativa - LIE e também em seus arredores, aproveitando o caráter móvel das ferramentas, ocorrendo no contra-turno das aulas.

As atividades foram desenvolvidas nos encontros presenciais, observando-se o seguinte critério: primeiramente, no início de cada encontro, era explicado o que ia ser estudado, rememorando os conceitos trabalhados no encontro anterior, através de questionamentos conjuntos. Essa ação proporcionou a sondagem constante de como os alunos estavam compreendendo os conteúdos e temas vivenciados previamente, além de permitir a formação de um espaço de discussão com todo o grupo. 
Posteriormente, eram exibidos vídeos, ministradas aulas expositivas e conduzidas discussões sobre os conteúdos e, em seguida, os alunos eram questionados sobre os temas vistos nos recursos, além de serem promovidos diálogos e conversações, objetivando ampliar e analisar a compreensão das temáticas em destaque.

Cada aluno teve à disposição um netbook com acesso à Internet via Wi-Fi. Em alguns momentos, os discentes utilizaram o smartphone de uso pessoal, por sua própria iniciativa. Foram selecionadas algumas ferramentas da Internet que proporcionassem a interatividade e o trabalho em grupo, como aplicativos de produção de vídeos, além da criação de um grupo no Facebook e no site de busca Google.

Os assuntos considerados na produção dos vídeos dos alunos foram constituídos a partir de uma aula em campo pelos arredores da escola, apresentando como objetivo, a tomada de consciência e o papel de cada um na sociedade, sendo estes relacionados ao que vinha sendo desenvolvido nas aulas de formação. Os dados como: fotos, registros, produções dos alunos, dentre vídeos, documentários, entrevistas foram coletados a partir do desenvolvimento dessas atividades em grupo. Estes foram analisados a partir de aspectos comuns que demonstraram a postura ativa do aluno, em que houve iniciativa em realizar atividades e tomar decisões.

\section{Resultados e discussões}

Os resultados desse estudo surgiram dos exemplos de trechos da transcrição de vídeos e de áudios analisados após a coleta de dados, se demonstrando através de produções, atitudes, decisões e gestos. Os diálogos foram transcritos de forma literal, razão pela qual podem apresentar erros ortográficos, gramaticais e de concordância.

Durante o desenvolvimento do projeto, enquanto os grupos produziram os vídeos e faziam o apanhado das fotos, entrevistas e o material coletado na aula de campo, o aluno $\mathrm{M}$ demonstrou habilidades com o desenho, e um dos colegas sugeriu a constituição de uma mascote para o grupo de alunos monitores. $M$ interessou-se pela sugestão e, logo, rascunhou várias personagens, demonstrando uma relação com o conteúdo da sustentabilidade. As personagens exibiam características de heróis e tinham, como principal objetivo, o desenvolvimento sustentável.

Através desse exemplo, pode-se perceber que houve aspectos do protagonismo estudantil, tendo em vista que o educando apresentou a iniciativa de fazer uma produção com a ajuda do colega, objetivando concretizar o que estava sendo desenvolvido na teoria. Na Figura 1, está exposta a mascote idealizada pelo aluno e que, em votação, foi selecionada para representar o grupo.

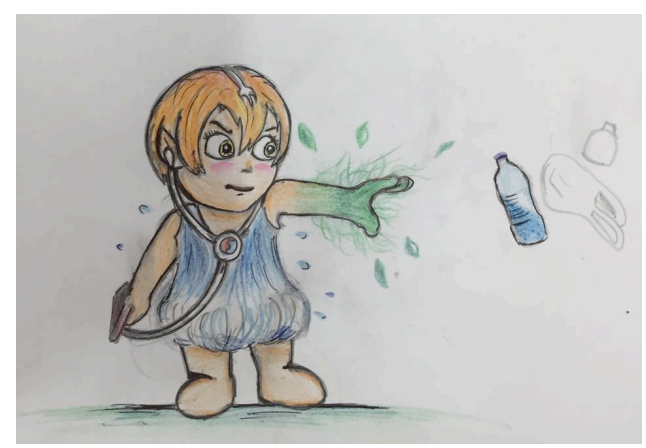

Figura 1. Mascote escolhida. 
Destaca-se outra situação que favoreceu o protagonismo dos alunos, em que eles decidiram qual personagem iria caracterizar o grupo. Descentralizando o processo, no qual só o professor decide, estes puderam escolher, decidir e conduzir as atividades, trazendo o processo de ensino e de aprendizagem para perto de sua realidade.

Depois de escolhida a personagem, o grupo propôs uma votação, que foi vinculada ao Facebook, para escolha do nome da mascote que representaria o grupo. No exemplo 1, registra-se um trecho da negociação dos alunos acerca da personagem, constituindo um espaço dinâmico de diálogo e relacionando-se a identificação da personagem ao assunto estudado durante as formações, tais como Flora e Sustendyn. Enquanto a aluna E inicia a interação manifestando a sua opinião e explicando o porquê da escolha, a aluna $\mathrm{K}$ mostra-se interessada pela mesma denominação, demonstrando que foi estabelecido, entre ambas, um ambiente dinâmico de troca de conhecimentos.

Exemplo 1. Motivo da escolha do nome da mascote.

Aluna E: Vou colocar o nome dela de Sustendyn, porque tem a ver com tudo que estamos estudando aqui e com o que temos aprendido.

Aluna K: Concordo com o que a aluna E falou; esse nome tem relação com o que estamos aprendendo.

O protagonismo manifestou-se a partir de atitudes independentes, contudo, também envolveu a mudança de papel e de contextos organizacionais, nos quais o aluno passou a conduzir as atividades escolares. Essa ampliação de função pode ser notada, principalmente, na aula em campo, quando os alunos conseguiram registrar imagens com o tablet em uma entrevista com uma antiga moradora da cidade sobre as mudanças ocorridas no município nos últimos anos. Os recursos facilitaram o desenvolvimento da entrevista, ao registrar material para produção de um vídeo.

Nesse exemplo, pode-se perceber que os alunos conseguiram ultrapassar o papel de aluno, para uma função de atuação, em que um pode ser repórter, outro filmador, desempenhando, assim, papéis além do que eles exercem em seu dia a dia. Na Figura 2, demonstra-se um momento da aula em campo, na qual os alunos entrevistaram uma antiga moradora da cidade, utilizando um smartphone como recurso tecnológico.

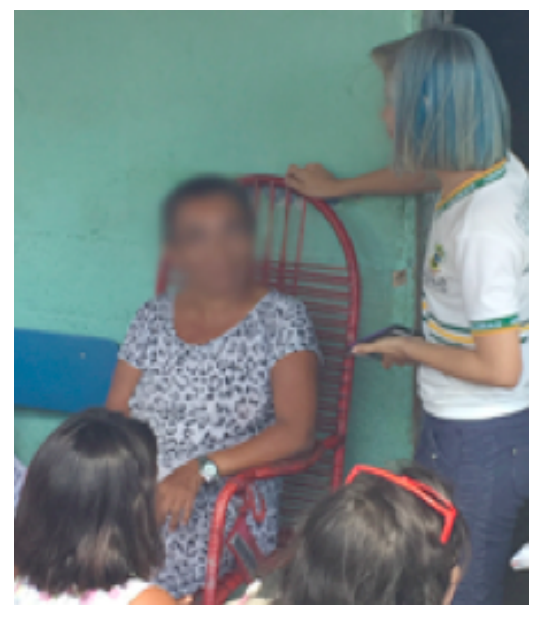

Figura 2. Alunos entrevistando antiga moradora. 
A formação, o trabalho desenvolvido pelos alunos e as ações nas quais foi evidenciado o protagonismo estudantil demonstraram o desenvolvimento das atividades com duas caraterísticas, que foram o ativismo estudantil e a autonomia. O protagonismo foi estabelecido a partir da atuação e da participação dos alunos nos processos de ensino e de aprendizagem, sendo estes autores do próprio conhecimento, e se estendeu em ações que ansiavam melhorias para a comunidade.

O exercício do protagonismo estudantil, em que os aprendentes conseguiram participar e atuar em sua aprendizagem, apresentou também características voltadas para a ação social, onde os alunos buscaram transformar a realidade em que estavam inseridos ao adotar práticas ativistas. A partir dos estudos, aulas teóricas, práticas, pesquisas e produção de material utilizando a tecnologia como recurso facilitador, os alunos passaram a tentar transformar a realidade educacional da qual fazem parte.

No desenvolvimento da produção de um vídeo, os discentes levantaram questões sobre a limpeza dos arredores da escola, procurando descobrir quem depositou o lixo em determinados locais e ainda organizaram movimentos para reverter a situação. Enquanto reviam as fotos, filmagens e registros da aula em campo, os discentes refletiam sobre o que podiam fazer para deslocar as ideias sustentáveis para dentro da escola. Essas ações podem ser observadas no exemplo 2, a seguir.

\section{Exemplo 2. Discussão sobre lixo na escola.}

Aluno R: Olha só quanto lixo dentro da escola. Aluna A: Engraçado que eu nunca tinha visto. Alunos R: É mesmo! Antes das aulas, eu passava aqui todo dia e não percebia quanto lixo acumulado tinha aqui pertinho da gente. Aluna A: Vamos falar com a diretora.

Aluno R: Se cada sala ficasse responsável por limpar o que sujasse.

Aluna I: Mas como vamos saber quem sujou?

Nesse diálogo, percebe-se o interesse dos alunos em resolver a situação do lixo em sua comunidade escolar, o que, posteriormente, acarretou o desenvolvimento de um projeto maior, juntamente com a professora de Ciências. O respectivo projeto, efetivado com a parceria entre professor e alunos, resultou na limpeza completa do ambiente, com plantio de novas mudas, como será demonstrado na figura 3 .

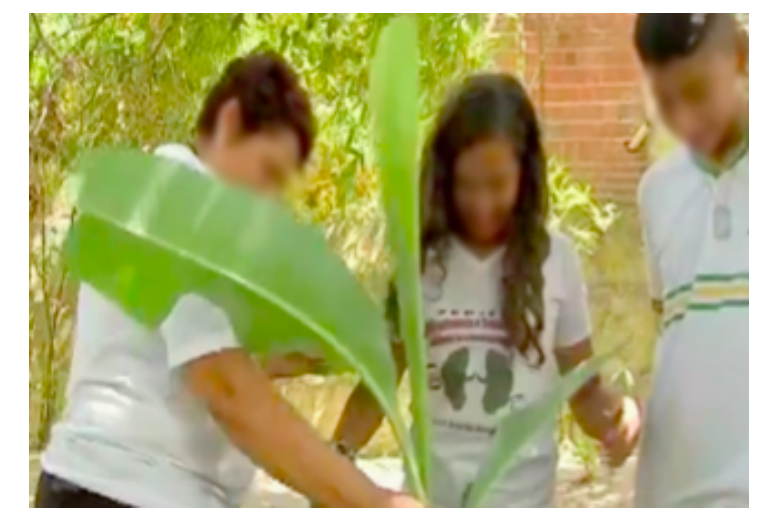

Figura 3. Alunos plantando mudas no bosque 
VI Congresso Brasileiro de Informática na Educação (CBIE 2017)

Anais do XXIII Workshop de Informática na Escola (WIE 2017)

A seção seguinte desenvolve as principais discussões e considerações conclusivas do estudo, além de propor estudos futuros correlacionados.

\section{Considerações finais e estudos futuros}

A partir das vivências dos alunos, procurou-se relacionar a práxis com base em questões teóricas, objetivando responder à pergunta inicial da pesquisa: Como as tecnologias digitais podem facilitar o processo de protagonismo em educandos do Ensino Fundamental?

Um aspecto importante diz respeito aos registros em filmagens, onde os detalhes, os gestos e os diálogos dos alunos puderam ser percebidos, facilitando a percepção quanto à interação dos participantes. As considerações finais são elencadas e relacionadas às categorias utilizadas na análise dos dados e a partir dos três objetivos específicos da pesquisa. No objetivo que visou definir parâmetros identificadores do protagonismo estudantil, as atividades foram desenvolvidas em grupo e com o uso de netbooks e tablets, além dos smartphones dos alunos, por iniciativa deles.

Como formadoras também da turma, as pesquisadoras puderam favorecer vivências que promoveram interações, além de agirem como um canal de assistência e também de desafio por meio de frequentes questionamentos. Sendo assim, os parâmetros identificadores da mediação e do protagonismo a partir deste estudo foram: espaços de diálogos entre o aprendente e pares e/ou alguém mais experiente; e compreensão conjunta e mediação, ou seja, através das ações intermediadas entre sujeito e objeto.

O papel exercido pelas pesquisadoras demonstrou a função mediadora e crucial do professor ao fomentar momentos de discussão junto aos seus alunos, promovendo, dessa forma, situações desafiadoras que favoreceram a mudança de postura dos discentes, visto que saíram da posição de expectadores para protagonistas, atuando, entrevistando, dando sugestões e produzindo. Essas vivências possibilitaram o surgimento do protagonismo e acarretaram, consequentemente, um processo mais qualitativo de aprendizagem.

Com relação ao objetivo específico de descrever as características do contexto no qual o protagonismo ocorre, o ambiente em que as emergências de mediação foram facilitadas desenvolveu-se a partir de atividades que ofereceram aos alunos a oportunidade de participar de seu processo de ensino e de aprendizagem de forma mais autoral.

As opiniões e sugestões dos alunos eram aceitas e incentivadas, constituindo um contexto de diálogo e de conversação entre os grupos, além de promover o protagonismo dos aprendentes. O tema trabalhado, no caso a sustentabilidade, por ser atual e discutido no meio educacional, social e cultural dos alunos, também criou esse ambiente propício ao desenvolvimento, visto que foi passível de discussões e de questionamentos.

Através do estudo, percebeu-se temas que envolveram a comunidade escolar e, a partir disso, os participantes tentaram mudar o espaço de que faziam parte, por meio de posturas ativistas, além de agir com autonomia para realizar mudanças e sugerir elementos que julgavam facilitar o processo e a sua caminhada. 
Dessa forma, o protagonismo emergiu a partir do momento em que os discentes perceberam que poderiam atuar como autores dos seus processos de aprendizagem, sendo produtores do próprio conhecimento e com a possibilidade de transformar o meio em que viviam. Outros contextos fomentadores do protagonismo foram as vivências estabelecidas a partir da mediação com os colegas e com pessoas mais experientes, além de situações constituídas a partir do desenvolvimento de conteúdos próximos à realidade social dos educandos.

Como sugestões de estudos futuros, têm-se a ampliação da pesquisa com outros tipos de recursos digitais e aplicativos específicos em outros níveis de ensino. Ainda, outra alternativa de estudo futuro é a promoção do acesso às tecnologias digitais aos alunos com alcance mais restrito destas, como forma de verificar os níveis de participação e de envolvimento em meio às possibilidades oferecidas por tais recursos.

A relação entre as TIC e os processos de ensino e de aprendizagem são uma realidade inevitável e devem ser caracterizados pela mediação entre docentes, aprendentes e os recursos tecnológicos de forma estruturada e pedagogicamente organizada. Espera-se, portanto, que este estudo possa despertar nos alunos posturas de protagonismo, trazendo, sobretudo, contribuições e inovações para esse contexto pedagógico aliado ao uso das tecnologias digitais, que se constitui um grande interesse no contexto atual.

\section{Referências}

Baptista, T. B. E; Vieira, M. (2015) “A utilização das Tecnologias da Informação e Comunicação nos projetos educacionais interdisciplinares". Anais do XXI Workshop de Informática na Escola. Maceió, 2015.

Bogdan, R. C.; Biklen, S. K. (1994) "Investigação qualitativa em educação". Porto: Porto Editora.

Bonilla, M. H. S. (2012) "A presença da cultura digital no GT Educação e Comunicação da Anped". Revista Teias, v. 13, n. 30, p. 23.

Colaço, V. F. R. (2001) "Interações em sala de aula: um estudo da atividade discursiva de crianças em séries iniciais”.Tese (Doutorado em Educação) - Programa de PósGraduação em Educação, Universidade Federal do Rio Grande do Sul, Porto Alegre.

Costa, A.C.G. (2000) "Protagonismo juvenil: adolescência, educação e participação democrática". Salvador: Fundação Odebrecht.

Kreijns, K.; Kirschner, P. A.; Jochems, W. (2003) "Identifying the pitfalls for social interaction in computer-supported collaborative learning environments: a review of the research". Computers in human behavior, v. 19, n. 3, p. 335-353.

Meira, L. (1994). "Análise microgenética e videografia: ferramentas de pesquisa em psicologia cognitiva". Temas em Psicologia, v. 2, n. 3, p. 59-71.

Meira, L.; Spinillo, A. G. (2006). "Psicologia cognitiva: cultura, desenvolvimento e aprendizagem”. Recife: Universitária. 
VI Congresso Brasileiro de Informática na Educação (CBIE 2017)

Anais do XXIII Workshop de Informática na Escola (WIE 2017)

Nascimento, K.A.S; Castro-Filho, J.A. (2016). "Dispositivos móveis na educação: ensinamento e aprendendo em diferentes contextos". In: XXVII Simpósio Brasileiro de Informática na Educação, Uberlândia, p.1225-1234.

Suanno, M.V.R. (2016). "Novas Tecnologias de Informação e Comunicação: reflexões a partir da Teoria Vygotskyano". Disponível em: <http://abed.org.br/seminario2013/texto16.htm>. Acesso em 16 de Fevereiro de 2017.

Resta, Paul; Laferrière, T. (2007) "Technology in support of collaborative learning". Educational Psychology Review, v. 19, n. 1, p. 65-83.

Valente, J. A. "Aprendizagem ativa no ensino superior: A proposta da sala de aula invertida”.Disponívelem:http://www.unifebe.edu.br/site/docs/arquivos/noticias/2014/ Valente. Acesso em 10/04/2017.

Vygotsky, L. S. A (1994). "Formação social da mente”. São Paulo: Martins Fontes.

Warschauer, M. (2006). “Tecnologia e inclusão social”. São Paulo: SENAC.

Wertsch, J. V.; Del Rio, P.; Álvarez, A. (1998) “Estudos socioculturais da mente”. Porto Alegre: Artmed. 